\title{
FOOD AND DRUG INTERACTIONS: A GENERAL REVIEW
}

\author{
Semih Ötles ${ }^{\bowtie}$, Ahmet Senturk \\ Department of Food Engineering, Ege University of Izmir \\ 35100 Bornova Izmir, Turkey
}

\begin{abstract}
Although it is well known and identified that drug-drug interactions exist, the recognition of importance of food and drug interactions to practice has been growing much slower. On the other hand, drug-food/nutrient interactions continue to grow with the common use of medications. Beside the awareness of this type of interactions, food-drug interaction studies are critical to evaluate appropriate dosing, timing, and formulation of new drug candidates. Drug-food interactions take place mechanistically due to altered intestinal transport and metabolism, or systemic distribution, metabolism and excretion. In addition, some people have greater risk of food and drug interactions who have a poor diet, have serious health problems, childrens and pregnant women. In this article, basic informations about importance, classifications, transporters and enzymes of drug and nutrient interaction are given and some specific examples of both drug and nutrients and influences on each other are included.
\end{abstract}

Key words: food, drug, nutrients, interaction

\section{INTRODUCTION}

Medications are used commonly to treat acute and chronic illness. Many people can obtain new drugs improved by research and novel technology [Bobroff et al. 2009]. Medications should have some important attributes in general. They should be extremely specific in their effects, have the same predictable effect for all patients, never be affected by concomitant food or other medications, exhibit linear potency, be totally non-toxic in any dosage and require only a single dose to affect a permanent cure [Bushra et al. 2011]. Medications could help people to live more healthy. Although medicines are often prescribed, it is important to realise that they must still be used with caution [Bobroff et al. 2009].

There are too many potential drug-nutrient interactions (DNIs) due to the widespread use of patent medicines along with the broad variability in nutrition status, dietary habits, food composition, and dietary supplement use [Boullata and Hudson 2012]. Drug-nutrient interaction is defined as an alteration of kinetics or dynamics of a drug or a nutritional element, or a compromise in nutritional status as a result of the addition of a drug [Braun 2012].

Another comprehensive definition of drug-nutrient interaction is that it is an interaction resulting from a physical, chemical, physiologic, or pathophysiologic relationship between a drug and a nutrient, multiple nutrients, food in general, or nutritional status [Boullata 2010].

Concurrent use of drugs increases the chance of drug interactions, but no-one knows what the interactions of all these drugs are. However, research on drug-nutrient interactions is very limited and further research is needed in some cases, to check the findings. Research trials may produce conflicting information and sometimes the research has been carried out into

\semih.otles@ege.edu.tr 
only one drug in a group, and we can only suspect that others have the same effect. Some individuals are more susceptible to loss of nutrients than others, and they are more likely to suffer from side effects [Moss 2007].

A food-drug interaction can prevent a medicine from working the way it should or can cause a side effect from a medicine to get worse or better. Besides, it can cause a new side effect [FDA 2013].

\section{TYPES OF DRUG-NUTRIENT INTERACTIONS}

DNIs can be mechanistically called in pharmaceutic, pharmacokinetic and pharmacodynamic terms (Fig. 1). Pharmaceutical interactions involve physicochemical reactions that occur in a delivery device like enteral feeding tube or within the gastrointestinal lumen. These can affect the bioavailability of a drug or nutrient. Bioavailability is an important pharmacokinetic parameter which is correlated with the clinical effect of most drugs [Bushra et al. 2011]. For example, with the chelation in the presence of enteral nutrition formula, ciprofloxacin bioavailability can be significantly reduced [Boullata and Hudson 2012].

Drugs and nutrients can influence signal transduction pathways that ultimately impact drug-metabolizing enzymes and transporters through receptor-mediated gene expression. The more that is known about drugs serving as substrate, inducer, or inhibitor of various transporters and enzymes in various tissues, the closer that direct or indirect interaction with nutrients that influence these same proteins can be determined or predicted.

Pharmacokinetic interactions influence the disposition of a drug or nutrient in the body and involve effects on absorption, distribution, metabolism and excretion [Lourenço 2001]. Pharmacodynamic interactions involve the clinical effect of a drug or physiologic effect of a nutrient. Qualitative or quantitative measures of drug action or of nutritional status help to define pharmacodynamic interactions [Boullata 2010].

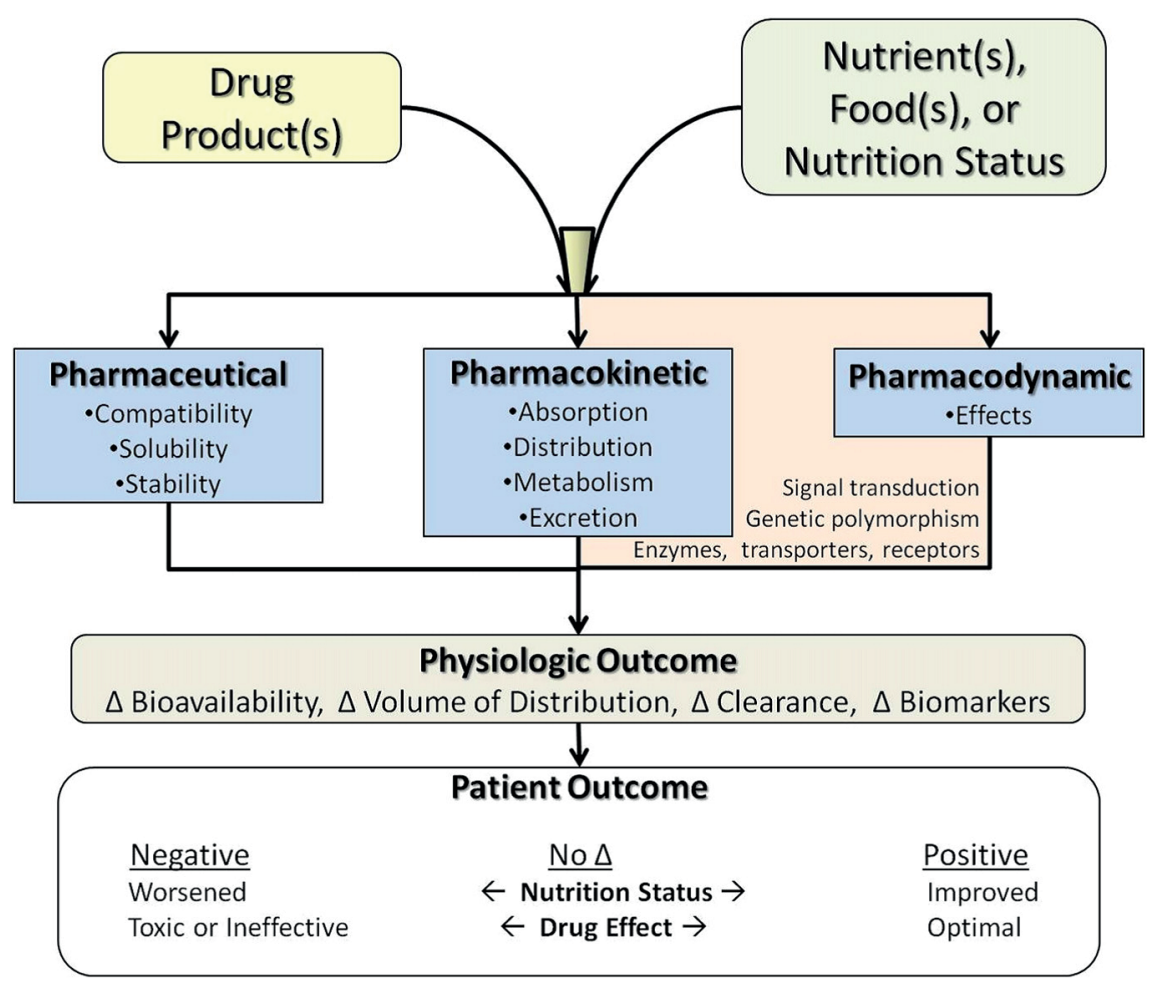

Fig. 1. Working model of drug-nutrient interactions [Boullata and Hudson 2012] 


\section{HOW DRUGS REACT IN THE BODY}

In order to understand food/drug and drug/nutrient interactions, it is important to understand how drugs work in the body. There are four stages of drug action for medicines administered orally:

- Stage 1. The drug dissolves into a useable form in the stomach.

- Stage 2. The drug is absorbed into blood and is transported to its site of action.

- Stage 3. The body responds to the drug and the drug performs its function.

- Stage 4. The drug is excreted from the body either by the kidney, liver, or both [Bobroff et al. 2009].

\section{DRUG INTERACTION RISK FACTORS AND IMPORTANCE}

Most of people have the mistaken belief that being natural, all herbs and foods are safe. It could not be said that is true perspective. Constantly, herbs and foods may interact with medications normally taken that result in serious side reactions. Experts suggest that natural does not mean it is completely safe. The medication that is taken by mouth travels through the digestive system in the same way as food and herbs taken orally do. When drugs and certain foods are taken at the same time, they might interact in such a way that decrease the effectiveness of the ingested drug or reduce the absorption of food nutrients. High-risk patients, such as the elderly patients taking three or more medications for chronic conditions, patients suffering from diabetes, hypertension, depression, high cholesterol or congestive heart failure should be especially monitored for such drugfood interactions [Yaheya and Ismail 2009].

Insufficient nutritional status can impair drug metabolism. Some people at higher risk for drug-nutrient interactions. They are who [Zyl 2011]:

- have impaired hepatic, renal or gastro-intestinal function

- are nutritionally compromised due to chronic disease

- have recent weight loss or dehydration

- are on multiple and prolonged drug therapy

- are at the extremes of age with changes in lean body mass, total body fluids and plasma protein concentration.
Although the term DNI often carries a negative connotation, some interactions can be considered positive in effect. Whether positive or negative, DNIs have erroneously been considered less relevant than drugdrug interactions; a comparison of views is interesting. Even though not the case initially, interactions between drugs or one itself have long been recognized as influencing patient outcomes via altered drug disposition and effect. Drug interactions contribute to adverse drug effects, leading to hospitalizations and even to withdrawal of approved drugs from the market. During 4-year period, it is seen from 20 million patients suggestion that nearly 250,000 adverse drug reactions occurred when evaluating of several database. Although nutritional disease ranked in the top five comorbid conditions among hospitalized patients, DNIs has not yet been determined in this groups. The science of describing drug-drug interactions has evolved considerably, to the point where they are widely recognized, identified, and managed in practice. In part, this is supported by the drug development and approval process. Conversely, the recognition of DNIs' importance to practice has grown much slower. The US Food and Drug Administration (FDA) does not include an evaluation of DNIs in its guidance process for drug development. This guidance document does provide criteria on determining the significance of an interaction (i.e., degree of change in biomarker or parameter) so it could be applied to DNIs [Boullata and Hudson 2012].

When the risk of interactions is mentioned, there is oftenly some doubt in people's mind about taking drugs on a full or empty stomach or using alcohol with drugs. These factors are described briefly below. In addition, grapefruit juice is an significant drink that has been subject of many scientific studies related with the food and drug interactions. For this reason, it is useful to mention here, grapefruit juice in particular.

\section{Taking drugs on a full or empty stomach}

The effects of some medicines can change when using them on a full or empty stomach. In addition, some medicines will upset the stomach, and if there is food in the stomach, that can help reduce the upset. If medicine label has not got directions of use, the patients must ask their doctor or pharmacist if it is best to take medicines on an empty stomach, with food, or after a meal. 


\section{Taking drugs with alcohol}

The alcohol can affect the work of medications in the basic conditions such as [FDA 2013]:

- swallowing medicine with alcohol

- drinking alcohol after medicine has been taken

- taking medicine after alcohol.

Alcohol affects body processes and interacts with many drugs. It influences many types of medications especially antidepressants and other drugs that affect both brain and nervous system. For example, taking alcohol with metronidazole can cause flushing, headache, palpitations, nausea and vomiting [Yaheya and Ismail 2009]. Patiens should talk to their doctor about any alcohol that they use or plan to use.

\section{Grapefruit juice}

Grapefruit juice and drug interactions are well known interactions as compared to other nutrients. However, its influence on all drugs is not known. Grapefruit juice blocks cytochrome P450 and IA2 (CYP3A4 and CYP1A2) in the intestinal area [Tamer and Karaman 2006]. This juice should not be taken with certain blood pressure-lowering drugs or cyclosporine for the prevention of organ transplant rejection. The reason is that grapefruit juice can cause higher levels of those medicines in the body, making side effects from the medicine more likely. The juice can also interact to cause higher blood levels of the anti-anxiety medicine Buspar (buspirone); the antimalaria drugs Quinerva or Quinite (quinine); and Halcion (triazolam), a medication used to treat insomnia [Avoiding... 2013]. Excessive ingestion of grapefruit juice increases the bioavailability of lovastatin, atorvastatin and simvastatin by 1400,200 and $1500 \%$, respectively. This may lead to drug accumulation and the possible development of adverse effects [Scheen 2007]. The components which lead to all such negativite reactions in grapefruit juice are defined as naringin, naringenin, furanokumarin, bergapten (5-methoxypsoralen) and flavonoids [Tamer and Karaman 2006].

\section{CLASSIFICATIONS}

Drug-nutrient interactions could be classified into one of five broad categories (Table 1). The many types of drug-nutrient interactions could thus be categorized with each having an identified precipitating factor
Table 1. Classification of drug-nutrient interactions [Boullata 2010]

\begin{tabular}{lll}
\hline $\begin{array}{l}\text { Precipitating } \\
\text { factor }\end{array}$ & $\begin{array}{l}\text { Object of } \\
\text { the interaction }\end{array}$ & $\begin{array}{l}\text { Potential } \\
\text { consequence }\end{array}$ \\
\hline Nutritional status & drug & $\begin{array}{l}\text { treatment failure } \\
\text { or drug toxicity }\end{array}$ \\
$\begin{array}{l}\text { Food or food } \\
\text { component }\end{array}$ & drug & $\begin{array}{l}\text { treatment failure } \\
\text { or drug toxicity }\end{array}$ \\
$\begin{array}{l}\text { Specific nutrient } \\
\text { or other dietary sup- } \\
\text { plement ingredient }\end{array}$ & drug & $\begin{array}{l}\text { treatment failure } \\
\text { or drug toxicity }\end{array}$ \\
$\begin{array}{l}\text { Drug } \\
\text { nutritional status }\end{array}$ & $\begin{array}{l}\text { altered nutritional } \\
\text { status }\end{array}$ \\
Drug & specific nutrient & $\begin{array}{l}\text { altered nutrient } \\
\text { status }\end{array}$ \\
\hline
\end{tabular}

and an object of the interaction. In some cases, the drug is the precipitating factor (i.e., causing changes to nutritional status), while in others the drug is the object of the interaction (i.e., changes in drug disposition or effect result from a nutrient, food, or nutritional status). In the event of the precipitating factor produces significant change in the object of the interaction,

Table 2. Location and mechanisms of drug-nutrient interactions [Boullata 2010]

\begin{tabular}{lll}
\hline Site of interaction & Consequencey & $\begin{array}{l}\text { Mechanism } \\
\text { of interaction }\end{array}$ \\
\hline $\begin{array}{l}\text { In drug (or nutrient) } \\
\text { delivery device } \\
\text { or gastrointestinal } \\
\text { lumen }\end{array}$ & $\begin{array}{l}\text { reduced } \\
\text { bioavailability }\end{array}$ & $\begin{array}{l}\text { physicochemi- } \\
\text { cal reaction } \\
\text { and inactivation }\end{array}$ \\
$\begin{array}{l}\text { Gastrointestinal } \\
\text { mucosa }\end{array}$ & $\begin{array}{l}\text { altered } \\
\text { bioavailability }\end{array}$ & $\begin{array}{l}\text { altered transporter } \\
\text { and/or enzyme } \\
\text { function }\end{array}$ \\
$\begin{array}{l}\text { Systemic circulation } \\
\text { or tissues }\end{array}$ & $\begin{array}{l}\text { alter distribution/ } \\
\text { effect }\end{array}$ & $\begin{array}{l}\text { altered trans- } \\
\text { porter, enzyme, } \\
\text { or other physi- } \\
\text { ologic function }\end{array}$ \\
& & $\begin{array}{l}\text { antagonism, } \\
\text { impairment, } \\
\text { organs of excretion } \\
\text { of elimination }\end{array}$ \\
\hline
\end{tabular}


drug-nutrient interactions are considered as important. Interactions that need to be totally avoided are not common; instead close monitoring with modification to the dosing schedules is usually all that is necessary. The nature of any physicochemical or physiologic interaction and its mechanism might be further classified to help in predicting and preventing their occurrence (Table 2). Mechanisms of an interaction relate to the physicochemical attributes of the medication and of the food or nutrient, within the environmental matrix. The consequence of an interaction (altered disposition of a drug or nutrient) is linked to its location. For example, at the gastrointestinal mucosa, an influence on membrane transporters and/or metabolizing enzymes can alter the bioavailability of a drug or nutrient. Another dimension to be considered is that physiologic manifestations of a drug-nutrient interaction may differ based on gene polymorphism (e.g., methotrexate and folic acid). The role of polymorphisms in nuclear receptors, metabolizing enzymes, and other proteins needs to be taken into account [Boullata 2010].

\section{FOOD AND DRUG TRANSPORTERS}

The investigation of the effects of drug transporters on drug disposition has been continued for many years [Custodio et al. 2008]. The oral administration of drugs to patients is convenient, practical, and preferred for many reasons. But oral administration of drugs can lead to limited and variable oral bioavailability because of absorption across the intestinal barrier. Drug absorption across the gastrointestinal tract is highly dependent on affinity for membrane transporters as well as lipophilicity. On the other hand, the liver plays a key role in the clearance and excretion of many drugs. Hepatic transporters are membrane proteins that primarily facilitate nutrient and endogenous substrate transport into the cell via uptake transporters, or protect the cell by pumping out toxic chemicals via canalicular transporters. As a result, drug transporters in both the gut and the liver are important in determining oral drug disposition by controlling absorption and bioavailability.

Until recently, it is not much considered to the possibility that food and food components could cause significant changes to the extent of drug absorption via effects on intestinal and liver transporters. Now, it is well known that drug-food interactions might influence the pharmacokinetics of prescribed drugs when used with food. Phytochemicals which are involved in common foods, such as fruits and vegetables contain a large variety of secondary metabolites. Many of them are known as healthy and harmless. However, we know little about the processes through which these phytochemicals (and/or their metabolites) are absorbed into the body, reach their biological target, and are eliminated. Recent studies show that some of these phytochemicals are substrates and modulators of specific members of the superfamily of $A B C$ transporting proteins. Indeed, in vitro and preclinical data in rats suggest that a variety of foodstuffs, including herbal teas and vegetables and herbs can modulate the activity of drug transporters. It is not yet known whether these effects are predictive of what will be observed clinically [Fragoso and Esparza 2013].

\section{FOODS AND DRUG-METABOLIZING ENZYMES}

Drug-metabolizing enzymes (DMEs) include phase I cytochrome P450 (CYP) oxidative and phase II conjugative enzyme systems. CYP monooxygenases are important phase I enzymes. They catalyse different types of oxidative reactions and they are responsible for the metabolism of various drugs and many endogenous substrates (e.g. steroids, fatty acids and eicosanoids) [Yao et al. 2012]. The relative abundance of different CYP450 in human hepatic smooth endoplasmic reticulum has been determined as 30\% CYP3A $4,13 \%$ CYP1A2, 7\% CYP2E1, 4\% CYP2A6, 2\% CYP2D6, $20 \%$ CYP2C, and 1\% CYP2B6. In humans, the extent of drug metabolism varies with the individual CYP isozymes as follows, $50 \%$ of drugs are metabolized by CYP3A 4 , followed by $25 \%$ and $20 \%$ by CYP2D 6 and CYP2C family, respectively [Mukherjee et al. 2011].

In general, drugs and chemicals activities result in the formation of more water-soluble and less toxic metabolites under phase I oxidative metabolic reactions. On the other hand, some CYP enzymes such as CYP $1 \mathrm{~A} 1,3 \mathrm{~A}$, and $2 \mathrm{E} 1$ are involved in the metabolic activations of carcinogens such as benzo(a)pyrene, N-nitrosodimethylamine, and aflatoxin $\mathrm{B}_{1}$. Furthermore, CYP-mediated oxidative metabolism of the substrates may generate toxic electrophiles and reactive oxygen species (ROS). Some pathophysiological alterations 
have been reported to modulate some CYP enzymes in liver. For example, higher hepatic CYP2E1, CYP2B, CYP3A, and CYP4A expression was found in uncontrolled diabetes. Steatosis produced by high fat diets rich in polyunsaturated fatty acids and that induced by chemicals such as ethanol or $\mathrm{CCl} 4$ are established as the experimental models of diet and chemical-mediated liver injury, respectively. Those models have been reported to be associated with liver injuries via alteration of hepatic expression of drug-metabolizing enzymes such as CYP2E1 and CYP4A.

Phase II enzymatic reactions refer to conjugation reactions that involve the addition of the intracellular polar groups including glucuronate, glutathione, sulfate, glycine to the foreign molecules and function to eliminate electrophiles and ROS generated by phase I reactions, thereby protecting organisms against chemical insult. Microsomal UDP-glucuronosyltransferase (UGT) and cytosolic glutathione S-transferase (GST) are two important phase II enzymes that catalyze the conjugation reactions resulting in the formation of water-soluble glucuronate and glutathione conjugates to facilitate the excretion of xenobiotics [Yao et al. 2012].

Foods, such as fruits, vegetables, alcoholic beverages, teas, and herbs, which consist of complex chemical mixtures, can inhibit or induce the activity of drugmetabolizing enzymes [Fragoso and Esparza 2013]. Detailed information about the interactions of specific foods on dugs will be given in the following sections of this review.

\section{EFFECTS OF NUTRITIONAL STATUS ON DRUGS}

The presence of nutritional abnormalities might have an effect on drugs. Drug dosages may need adjustment based on actual body weight for some drugs. Based on actual, ideal, or an adjusted body weight corrected for lean body mass, other drugs can need to be dosed differently in obese, normal, and underweight patients. Somatic protein status may affect the dosing of medications that bind to somatic protein [Frankel 2003].

Pharmacokinetic and pharmacodynamic data in special patient populations usually focus on those with renal impairment, hepatic dysfunction, or unique lifestage attributes. Although the influence on drug metabolism has been recognised, drug disposition is much less frequently assessed based on nutritional status (e.g., protein-calorie malnutrition, obesity, micronutrient deficits). The nutritional status of subjects in clinical drug trials has not always been well described [Boullata 2010].

The influence that nutrition status might have on drug disposition and effect is included as one of the five broad categories in the classification of drug-nutrient interactions. In the way that a precipitating factor to the interaction, nutrition status might result in drug toxicity or drug treatment failure related to the malnutrition's degree. Related with other fields of drug-nutrient interactions, the data available to clinicians are limited for the influence of obesity on drug disposition and even less for PCM (protein-energy malnutrition) [Boullata 2010].

Several reviews about obesity and drugs are presented as regard to clas-specific considerations. In all these, antimicrobals in obesity get more attention and it is also been suggested in the case of antibiotics used in undernourished children.

\section{FOOD EFFECT ON DRUG DISPOSITION}

Oral drug administration concurrent with food intake can influence the rate and/or extent of drug absorption and alters the physicochemical conditions within the gastrointestinal tract. The latter is more clinically important varying with drug properties and meal characteristics. The ability to predict the effect of food on drug disposition has become more grounded. Prediction based on classifications of physicochemical drug properties (e.g. Biopharmaceutics Classification System [BCS] or the Biopharmaceutics Drug Disposition Classification System [BDDCS]) together with physiologic variables has become useful [Boullata 2010].

The FDA issued in 2002 a guidance entitled: "Food-Effect Bioavailability and Fed Bioequivalence Studies". High fat meals are recommended in this manual for food-effect studies, as meal conditions that $800-1000$ cal; $50-65 \%$ from fat, $25-30 \%$ from carbohydrates, and $15-20 \%$ protein are expected to provide the greatest effects on gastrointestinal physiology so that systemic drug availability is maximally affected. It is basically believed that food effects result from 
Table 3. Fruit-drug interactions [Fragoso and Esparza 2013]

\begin{tabular}{|c|c|c|}
\hline Fruit & Molecular target & Drug interactions \\
\hline Grapefruit & $\begin{array}{l}\text { inhibits CYP3A4, } \\
\text { CYP1A2, MRP2, } \\
\text { OATP-B and } \\
\text { P-glycoprotein }\end{array}$ & $\begin{array}{l}\text { calcium channel an- } \\
\text { tagonist, central nervous } \\
\text { system modulators, } \\
\text { HMG-CoA reductase, } \\
\text { immunosuppressants, } \\
\text { antivirals, phosphodiester- } \\
\text { ases-5 inhibitor, antihista- } \\
\text { mines, antiarrythmics } \\
\text { and antibiotics }\end{array}$ \\
\hline $\begin{array}{l}\text { Sevilla } \\
\text { orange }\end{array}$ & $\begin{array}{l}\text { inhibits CYP3A4, } \\
\text { P-glycoprotein, } \\
\text { OATP-A, OATP-B }\end{array}$ & $\begin{array}{l}\text { vinblastine, fexofenadine, } \\
\text { glibenclemida, atenolol, } \\
\text { ciprofloxacine, ciclo- } \\
\text { sporine, celiprolol, levo- } \\
\text { floxacin and pravastatin }\end{array}$ \\
\hline Tangerine & $\begin{array}{l}\text { stimulates CYP3A4 } \\
\text { activity and inhibits } \\
\text { P-glycoprotein }\end{array}$ & nifedipine, digoxina \\
\hline Grapes & $\begin{array}{l}\text { inhibits CYP3A4 } \\
\text { and CYP2E1 }\end{array}$ & cyclosporine \\
\hline Mango & $\begin{array}{l}\text { inhibits CYP1A1, } \\
\text { CYP1A2, CYP3A1, } \\
\text { CYP2C6, CYP2E1, } \\
\text { P-glycoprotein }\end{array}$ & $\begin{array}{l}\text { midazolam, diclofenac, } \\
\text { chlorzoxazone, verapamil }\end{array}$ \\
\hline Apple & $\begin{array}{l}\text { inhibits CYP1A1, } \\
\text { OATP family }\end{array}$ & fexofenadine \\
\hline Papaya & inhibits CYP3A4 & not documented \\
\hline
\end{tabular}

changes in drug solubility and other factors as listed by the FDA, such as food might: "delay gastric emptying; stimulate bile flow; change gastrointestinal $\mathrm{pH}$; increase splanchnic blood flow; change luminal metabolism of a drug substance; and physically or chemically interact with a dosage form or a drug substance". Additionally, it is also necessary to consider the fluidic environment and the resulting components present in the GI tract following a meal high in fat [Custodio et al. 2008].

By using Biopharmaceutics Classification System, in vitro data could be developed and so it can often predict drug disposition and food effects. There are four Biopharmaceutics Classification System classes based on drug solubility and intestinal permeability. Class II drugs have low solubility but high permeability and are expected more than drugs in the other three classes to have an enhanced extent of absorption when administered with food. The size of change in bioavailability can benefit to determine how clinically significant the difference between the fed and fasted states is. On the other hand, food will impair the absorption of drugs with poor permeability, despite adequate solubility (i.e. Biopharmaceutics Classification System Class III) [Boullata and Hudson 2012].

Some fruit-drug and vegetable-drug interactions are shown in Table 3 and Table 4 [Fragoso and Esparza 2013]. Cruciferous vegetables have been shown to up-regulate a number of cytochrome P450 enzymes in the livers and colons of rats. Apiaceous vegetables (carrots, parsley, celery, and fennel) lead to lower P450 activity. Grapefruit juice produces the most well-researched and clinically relevant (in humans) drug-food interactions by inhibiting intestinal

Table 4. Vegetable-drug intractions [Fragoso and Esparza 2013]

\begin{tabular}{|c|c|c|}
\hline Fruit & Molecular target & Drug interactions \\
\hline Broccoli & $\begin{array}{l}\text { inhibits CYP1A1, CYP2B1/2, } \\
\text { CYP3A4, CYP2E1, hGSTA1/2, } \\
\text { MRP1, MRP2, BCRP, UDP, } \\
\text { glucorosytransterases, dulfo- } \\
\text { transferases, quinone reductses } \\
\text { phenolsulfotransferases } \\
\text { induces: UDPglucuronosyl- } \\
\text { transferases, (UGTs), } \\
\text { sulfotransferases (SULTs) } \\
\text { ans quinone reductase (QRs) }\end{array}$ & not documented \\
\hline Spinach & possible inhibition of CYP1A2 & $\begin{array}{l}\text { heterocyclic aro- } \\
\text { matic amines }\end{array}$ \\
\hline Tomato & $\begin{array}{l}\text { inhibits CYP1A1, CYP1B1, } \\
\text { UGP } \\
\text { increases UGT and CYP2E1 }\end{array}$ & $\begin{array}{l}\text { diethylnitrosa- } \\
\text { mine, N-methyl- } \\
\text {-N-nitrosourea } \\
\text { and } 1,2 \text { dimethyl- } \\
\text { hydrazine }\end{array}$ \\
\hline Carrot & $\begin{array}{l}\text { induces phenolsulfotrans- } \\
\text { ferases and ethoxycoumarin } \\
\text { O-deethylase ECD } \\
\text { inhibits CYP2E1 }\end{array}$ & not documented \\
\hline $\begin{array}{l}\text { Red } \\
\text { pepper }\end{array}$ & $\begin{array}{l}\text { inhibits CYP1A2, CYP2A2, } \\
\text { CYP3A1, CYP2C11, CYP2B1, } \\
\text { CYP2B2, CYP2C6 }\end{array}$ & $\begin{array}{l}\text { in vitro } \\
\text { and in vivo }\end{array}$ \\
\hline
\end{tabular}


cytochrome activity. The chemicals responsible for enzyme inhibition are furanocoumarins. This inhibitory effect is long-lasting, and requires the synthesis of new enzyme proteins for the "grapefruit juice effect" to disappear, and repeated juice intake amplifies the process. Thus, grapefruit juice ingestion can increase the absorption and blood levels of certain drugs, which can cause adverse effects, even overdose, to occur. On the other hand, drugs administered as pro-drugs may have less effectiveness, as the enzymes responsible for converting them into active metabolites are inhibited. While there are no current reports of "grapefruit seed extract" (touted as having antiparasitic and antimicrobial effects) causing similar alterations, this may change as more information becomes available [Robinson 2007].

Soy protein isolates reduce the expression and activity of the cytochrome P450 (CYP)-metabolizing isoenzyme CYP1A1 by a posttranslational reduction of the transcription factor AhR (aryl hydrocarbon receptor). Based on a gene array screening method, soy isoflavones can significantly upregulate two drug transporters and three phase I and two phase II enzymes [Boullata 2010].

The observed induction and inhibition of CYP enzymes by natural products in the presence of a prescribed drug has led to the general acceptance that natural therapies can have adverse effects. Herbal medicines such as St. John's wort, garlic, piperine, ginseng, and gingko, which are freely available over the counter, have given rise to serious clinical interactions when co-administered with prescription medicines. Such adversities have spurred various preclinical and in vitro investigations on a series of other herbal remedies, with their clinical relevance yet to be established [Fragoso and Esparza 2013]. Regarding intestinal metabolism, metabolic food-drug interactions have been widely reported with Cytochrome P450 3A4 (CYP3A4) receiving considerable attention. This is the expected case as numerous drugs marketed worldwide are metabolized by CYP3A4 [Custodio et al. 2008]. If we consider that CYP3A4 is responsible for the metabolism of more than $50 \%$ of clinical pharmaceuticals, all nutrientdrug interactions should be considered clinically relevant, in which case all clinical studies of drugs should include a food-drug interaction screening [Fragoso and Esparza 2013].

\section{EFFECTS OF DRUGS ON NUTRITION STATUS}

Some drugs can have an effect on a patient's nutritional status. The mechanisms for these effects are varied and are usually due to drug side effects [Frankel 2003]. A drug can enhance or inhibit nutrient bioavailability. Thus, it affects the nutritional status of individuals. For instance, elderly people, who are taking multiple medications for a long period of time are often found to be deficient in one or more nutrients. Other age groups, such as young children and adolescents, are also particularly at risk. There is a potential problem with drug-nutrient interactions in adolescents because their nutrient needs are higher than those of adults. Pregnant women and infants are the other groups also at particular risk.

The reason of these deficiencies is not only based on the chemical reactions between drugs and nutrients but also on the dose and duration of treatment/ exposure to the drug. Drugs can interfere with nutrient utilizations at several sites starting from the ingestion of the food to the final stage of excretion [Wunderlich 2004].

\section{Food intake and absorbtion}

The influence of medication on overall nutritional status can be due to many factors. Drugs can influence food intake, digestion, and absorption [Boullata 2010]. Many drugs can cause anorexia, alter taste and smell, cause nausea and vomiting, and ultimately affect overall food intake [Wunderlich 2004]. Nonsteroidal antiinflammatory agents, commonly used to treat arthritis, including aspirin, can cause irritation of the upper gastrointestinal mucosa and even cause ulcers. This can depress appetite and produce weight loss [Frankel 2003]. On the other hand, some anorectic drugs are used for weight loss and to treat obesity by reducing appetite. Examples are adrenergic and serotoninergic agents, which cause satiety, reduce appetite, and increase energy expenditure leading to weight loss. A good example for adrenergic drugs are amphetamines that stimulate secretion of norepinephrine and reduce food intake [Wunderlich 2004].

The using of chemotherapeutic agents to treat cancer can affect growing tissues, particularly the lining of the gastrointestinal tract (GIT). Nausea is a common side effect and can interfere with eating. Some patients 
can have oral and esophageal lesions and it can cause pain upon chewing and swallowing (odynophagia). Thus, this formations lead to limits oral intake. Antibiotics can suppress commensal bacteria, and this may result in overgrowth of other organisms such as Candida albicans. Overgrowth in the GIT may produce malabsorption and diarrhea. Overgrowth in the mouth may result in candidiasis or thrush, which can reduce oral intake [Frankel 2003].

Taste and smell are very important factors that influence food intake and can subsequently affect the nutritional status of individuals. Taste alteration (dysgeusia or hypogeusia) due to medications is very common. Some hypoglycemic agents like glipizide, the antimicrobials amphotericin B, ampicillin, and antiepileptic phenytoin are among the medications that alter taste perception. Other examples are given in Table 5 [Wunderlich 2004].

Many drugs reduce salivation and cause dryness of the mucus membranes. This can also inhibit oral intake. Nausea, vomiting, diarrhea, and constipation are ubiquitous side effects associated with most medications and even with placebo medications. Also, oral

Table 5. Examples of drugs that change taste perception [Wunderlich 2004]

\begin{tabular}{ll}
\hline \multicolumn{1}{c}{ Acetyl sulfasalicylic acid } & Griseofulvin \\
\hline Allopurinol & Lidocaine \\
Amphetamines & Lithium carbonate \\
Amphotericin B & Meprobamate \\
Ampicillin & Methicillin sodium \\
Amylocaine & Methylthiouracil \\
Benzocaine & Metronidazole \\
Captopril & Nifedipine \\
Chlorpheniramine maleate & D-penicillamine \\
Clofibrate & Phenindione \\
Diltiazem & Phenytoin \\
Dinitrophenol & Probucol \\
5-Fluorouracil & Sulfasalazine \\
Flurazepam (Dalmane) & Triazolam (Halcion) \\
\hline
\end{tabular}

intake of food may be reduced due to these effects [Frankel 2003].

Because of the presence of drugs, several mechanisms can affect nutrient absorption. Drugs can damage the intestinal absorptive surfaces including villi, microvilli, brush border enzymes, and the transport system. Also drugs can affect the absorption of nutrients by changing the GI transit time or the overall GI chemical environment. Absorption of micronutrients, vitamins and minerals, as well as macronutrients, protein and fat, are affected by the type, dosage, and strength of some drugs.

Many laxatives, mineral oil, and cathartic agents reduce transit time in the GI tract and may cause steatorrhea and loss of fat-soluble vitamins, A and E, and possibly calcium and potassium. Drugs containing sorbitol, such as theophyline solutions, can induce osmotic diarrhea and so shorten the transit time. Antacids change the $\mathrm{pH}$ of the stomach and cause chelating with some minerals, consequently reducing their absorption. Higher $\mathrm{pH}$ in the stomach reduces the absorption of iron, calcium, zinc, and magnesium [Wunderlich 2004].

\section{Weight gain and metabolism}

Several groups of drugs can increase appetite and consequently lead to weight gain. Anticonvulsants (caramazepine and valproic acid), antihistamines (cyproheptadine hydrochloride - Periactin), psychotropic drugs (chlordiazepoxide hydrochloride - Librium, diazepam - Valium, chloromazine hydrochloride Thorazine, meprobamate - Equanil), and corticosteroids (cortisone, prednisone) could be given as examples of such drugs. A synthetic derivative of progesterone, medroxyprogesterone acetate or megestrol acetate, used for the treatment of hormone-sensitive breast and endometrial cancer, may increase appetite, food intake, and weight gain [Wunderlich 2004].

Dronabinol (Marinol ${ }^{\circledR}$ ), also known as THC (from tetrahydracannabinols), the active principle in cannabis, is also used as an appetite stimulant. Oxandrolone (Oxandrin $\left.{ }^{\circledR}\right)$ is an anabolic steroid approved for weight gain. Megesterol (Megace $\left.{ }^{\circledR}\right)$ can enhance appetite and it is a progestin used to treat certain types of cancer. Cyproheptadine (Periactin ${ }^{\circledR}$ ) has been used to enhance appetite, although this is an off-label use and not an FDA-approved indication [Frankel 2003]. 
The formulation of drugs in lipid emulsion (e.g. in $10 \%$ soybean), contributes to a significant amount of additional energy intake. Other drugs (e.g. lorazepam, morphine, pancuronium) can change the bodyweight by decreasing the body's energy expenditure [Wunderlich 2004].

Besides drugs specifically indicated to affect changes in appetite, some drugs may affect appetite as a side effect. Several antidepressants have been observed to consistently increase or decrease appetite [Frankel 2003]. Several metabolic adverse effects (i.e., weight gain, hyperglycemia, dyslipidemia) have been associated with the use of the second-generation antipsychotics. An evaluation of a large database revealed that weight gain (increased BMI) was significantly more likely with the use of risperidone, quetiapine, and olanzapine compared with first-generation antipsychotic agents, while weight gain was less likely with aripiprazole, ziprasidone, and clozapine [Boullata 2010].

Some of the important functions of vitamins and several minerals are being coenzymes/cofactors in metabolic processes in the human body. As a result, certain drugs are targeted to these coenzymes (antivitamins) in order to reduce the activity of some enzymes in related metabolic reactions. Good examples of these drugs are methotrexate (MTX) for treating leukemia and rheumatoid arthritis; trimethoprim, used with sulfa for Pneumocystis carinii pneumonia; and aminopterin and pyrimethamine, used for treating malaria and ocular toxoplasmosis. Vitamin folate is a cofactor for the enzyme dihydrofolate reductase. It is necessary for nucleic acid biosynthesis and cell replication. This vitamin will be excreted because the drugs displace it from dihydrofolate reductase to reduce cell replication. Prescription for supplements for these patients should be cautioned and monitored. Another example is the anticoagulant drug, coumarin, which is a vitamin $\mathrm{K}$ antagonist [Wunderlich 2004].

\section{Nutrient excretion}

Competitive binding and altered reabsorption mechanisms can cause drugs to induce nutrient excretion. D-Penicillamine chelates with toxic metals, and with some other metals like zinc, eliminating it via urine. Ethylenediaminetetra-acetic acid (EDTA) has been shown to cause urinary excretion of zinc. Some diuretics, such as furosemide, ethacrynic acid, and triamterene, reduce the reabsorption of electrolytes and minerals such as calcium, magnesium, zinc, and increase renal excretion of these elements. The using of thiazide and loop diuretics can often cause sodium loss in the urine. Potassium-sparing diuretics spare potassium and magnesium loss but augment urinary sodium loss. Depletion of magnesium is associated with chemotherapeutic agents such as cisplatin. Therefore, magnesium supplement often is recommended between the chemotherapy treatments for these patients [Wunderlich 2004].

\section{MEDICINES EXHIBITING POOR BIOAVAILABILITY IN PRESENCE OF FOOD}

Drugs can be grouped as their chemical makeup or actions in the body. Different foods can interact with more than one class of drugs. If the patients are not sure which classes their medicines fall into, they must ask the doctor or pharmacist [Bobroff et al. 2009]. Some useful information and advices are given below that is about common used medicines.

\section{Antihistamines}

Antihistamines are used to treat or relieve symptoms of colds and allergies. They block the histamine the body releases when a substance (allergen) causes the symptoms of an allergic reaction. Some antihistamines can cause drowsiness [FDA 2013]. Also they may increase the appetite, which can lead to weight gain [Bobroff et al. 2009].

Brompheniramine, cetirizine and chlorpheniramine are some of the typical examples of this group medicines. People who take this drugs should avoid alcohol because it can add to any drowsiness caused by these medicines [FDA 2013]. Also, they should avoid sedating herbs (e.g., lemon balm, kava kava, california poppy, catnip, St. John's wort, skullcap, and valerian) which can increase the sedative actions of anti-allergy drug, causing drowsiness, disorientation, and serious lethargy [Wallace et al. 2013].

\section{Analgesics}

Analgesics are widely used drugs that relieve pain and they often cause stomach irritation [Bobroff et al. 2009]. Salicylates, including aspirin, have long been 
recognised to induce gastric distress. This may progress to anemia secondary to occult blood loss in patients who take large doses over an extended period of time. The potential for gastric distress is reduced when taken with meals or milk [McCabe et al. 2003].

Acetaminophen is a kind of example of analgesic. If three or more alcohol is consumed every day, it must be consulted with doctors to whether it should be used medicines with acetaminophen or other pain reliever/ fever reducers. Acetaminophen can cause liver damage. The chance for severe liver damage is higher if three or more alcohol drinks are used every day [FDA 2013].

\section{Antibiotics}

Antibiotics are used to treat bacterial infections. There are many different types of antibiotics [Bobroff et al. 2009]. They deplete folic acid, biotin and B complex vitamins and vitamin $\mathrm{K}$, Lactobacillus acidophilus and bifidobacteria. These are friendly bacteria that colonize the intestinal tract and support healthy digestion and immune function. The probiotic bacteria should be replaced with a supplement during and following use of this medication.

Mineral supplements (magnesium, calcium, zinc, iron, selenium, iodine) need to be taken at least 2 hours away from antibiotics, as they can bind to the drug and reduce its absorption [Wallace et al. 2013]. Penicillin and erythromycin are destroyed by stomach acid when taken with food. So it is most effective when taken on an empty stomach. However, food can reduce the chance of stomach irritation from these drugs [Bobroff et al. 2009]. If significant gastrointestinal distress occurs, these drugs can be taken with food, although that will alter the pharmacokinetics of the dose. Furthermore, before intake of dairy products, it should be well considered. Because milk products are among the few rich sources of riboflavin, as well as an easily consumed and inexpensive protein source [McCabe et al. 2003].

\section{Anticoagulants}

Anticoagulants slow the process of blood clotting. This can decrease risk of strokes in patients whose blood tends to clot too easily. These drugs, like warfarin (Coumadin), work by interfering with the use of vitamin $\mathrm{K}$ in blood clotting [Bobroff et al. 2009]. Vita$\min \mathrm{K}$ can make the medicine less effective. Warfarin can be taken on a full or empty stomach. Normal balanced diet with a steady amount of leafy green vegetables can be eaten, and it should be asked to doctor before making changes in the diet. Foods high in vitamin $\mathrm{K}$ include broccoli, cabbage, collard greens, spinach, kale, turnip greens, and brussel sprouts.

Cranberry juice or cranberry products can change the effects of warfarin while using anticoagulants. These products should be avoid while using warfarin. In addition, many dietary supplements and vitamins can interact with anticoagulants and reduce the benefit or increase of the risk of warfarin. Avoid garlic, ginger, glucosamine, ginseng, and ginkgo because they can increase the chance of bleeding. Moreover, avoiding alcohol is an important issue because it can affect the dose of warfarin [FDA 2013].

\section{ACE inhibitors (Angiotensin Converting Enzyme inhibitors)}

ACE inhibitors lower blood pressure or treat heart failure. They relax blood vessels so blood flows more smoothly and the heart can pump blood better. Some of the examples of these drugs are captopril, enalapril, lisinopril, moexipril, quinapril and ramipril.

Patients should take captopril and moexipril one hour before meals. In addition, ACE inhibitors can increase the amount of potassium in the body and too much potassium can be harmful and can cause an irregular heartbeat and heart palpitations. Some foods like bananas, oranges, green leafy vegetables contain large amounts of potassium. Thus, patients should avoid eating these foods or tell the doctor if they are taking salt substitutes with potassium, potassium supplements, or diuretics (water pills) [FDA 2013].

\section{Beta blockers}

Beta blockers are in widespread use for the treatment of a variety of cardiovascular diseases: these include stable and unstable angina pectoris, hypertension, acute myocardial infarction, congestive heart failure due to systolic or diastolic dysfunction, and the therapy and prevention of some arrhythmias [Auer 2004]. It should not be stopped that taking a beta blocker suddenly without talking to the doctor. If it is done, patients can get chest pain, an irregular heartbeat, or a heart attack. The doctor might tell users to decrease the dose gradually. 
Carvedilol and metoprolol are main types of this medications. Carvedilol should be taken with food to decrease the chance it will lower the blood pressure too much. This medicine should be taken extended release capsules in the morning with food and it should not crush, chew, or divide the capsule [FDA 2013].

\section{Diuretics}

Diuretics cause excretion of a higher amount of more urine and are often used to treat high blood pressure and fluid buildup. Some diuretics increase urine losses of minerals such as potassium, magnesium, and calcium while others limit mineral loss [Bobroff et al. 2009]. Bumetanide, furosemide and hydrochlorothiazide can be given as an example of these medications [FDA 2013]. Hydrochlorothiazide (HCTZ) depletes magnesium, folic acid, vitamin B6, zinc and coenzyme Q10. It should be accepted that a multiple vitamin and 30-90 mg coQ10 daily replace these nutrients. Many herbs are also contraindicated: alder, buckthorn, cascara sagrada, cleavers, dandelion root, digitalis, forskolin, ginseng (panax or Siberian), horsetail, licorice, St. John's wort and uva ursi. Thiazide diuretics decrease calcium loss in the urine due to actions on the kidneys. As a result, it may be less important for some people taking thiazide diuretics to supplement calcium than it is for other people. Patients should avoid taking calcium (above $400 \mathrm{mg}$ /day) or vitamin $\mathrm{D}$ (above $400 \mathrm{iu} /$ day) while taking this drug [Wallace et al. 2013].

\section{Antineoplasts}

Antineoplastic agents are used to treat several types of cancer. These drugs can irritate the cells lining the mouth, stomach, and intestines. Many cause nausea, vomiting, and/or diarrhea. The first folate antagonist recognized was methotrexate (Mexate $\AA$ ), which may also lower absorption of vitamins $\left(B_{12}\right.$ and carotene), fat, lactose, and calcium. Avoidance of milk products at the time of taking methotrexate is also advised. All of these can affect nutrient status [McCabe et al. 2003]. Supplementation of folic acid may be recommended for people taking this drug, but it should be asked to doctor before starting folic acid [Bobroff et al. 2009].

\section{Bronchodilators}

Bronchodilators treat and prevent breathing problems from bronchial asthma, chronic bronchitis, emphysema, and chronic obstructive pulmonary disease (COPD). These medicines relax and open the air passages to the lungs to relieve wheezing, shortness of breath, troubled breathing, and chest tightness [FDA 2013].

Some of the examples of these type of medications are albuterol and theophylline. Albuterol depletes calcium, magnesium and potassium. Avoid digitalis (foxglove) family herbs, which interact negatively with the medication [Wallace et al. 2013]. Using bronchodilators with foods and drinks that have caffeine can increase the chance of side effects, such as excitability, nervousness, and rapid heart beat. Avoiding alcohol is very important if using theophylline medicines because alcohol can increase the chance of side effects, such as nausea, vomiting, headache, and irritability [FDA 2013].

\section{Lipid-altering agents (Statins)}

Statins lower cholesterol by lowering the rate of production of LDL (lowdensity lipoproteins). Some of these medicines also lower triglycerides. Some statins can raise HDL-C (highdensity lipoproteins), and lower the chance of heart attack, stroke, or small strokes.

Atorvastatin, fluvastatin and lovastatin are the main examples in this group of medicines. Most statins can be taken on a full or empty stomach. Some statins will work better if taking them with an evening meal. In addition, more than one quart of grapefruit juice a day shouldn't be drunk if taking atorvastatin, lovastatin, or simvastatin. Large amounts of grapefruit juice can raise the levels of those statins in the body and increase the chance of side effects. Some statins do not interact with grapefruit juice. Thus, patients should ask their doctor or pharmacist. Moreover, people should avoid alcohol because it can increase the chance of liver damage [FDA 2013].

\section{Psychotropic agents}

There are many groups of psychiatric drugs according to several chemical classes and different mechanisms. Weight gain has been a clinically reported side 
effect in almost every class and is likely multifactorial in origin. Appetite stimulation, restricted physical activity, organized group activities with food, increased sleep patterns, and regain of previously lost weight are just a few possible contributing factors related to psychiatric hospitalization. Smoking is extremely prevalent among mental health patients, bringing increased requirements for certain nutrients such as vitamin $\mathrm{C}$ and lower intakes of other nutrients (e.g., folate and vitamin $\mathrm{B}_{12}$ ).

It is common in all these kind of medications to avoid alcohol. Alcohol can add to the side effects caused by these medicines, such as drowsiness [Mc-Cabe et al. 2003].

\section{CONCLUSION}

Food and drugs, both are necessary for good health, but they sometimes also bring side effects and risks when used at same time. Thus, the interactions need to be well identified. Generally, the effect of food on drugs results in a reduction in the drug's bioavailability; however, food can also alter drug clearance. Drugs can influence food intake, digestion, absorption and exrections. Much more research is needed for identification of this kind of interactions and pharmacists should be aware of the necessity of monitoring for potential drug-food interactions and advising patients regarding foods or beverages to avoid when taking certain medications.

\section{REFERENCES}

Avoiding drug interactions, 2013. [online], http://www. fda.gov/downloads/ForConsumers/ConsumerUpdates/ ucm096391.pdf [access: May 2013].

Auer J., 2004. Cardiovascular drugs. Handbook of drug interactions a clinical and forensic guide. Ed. A. Mozayani, P.L. ve Raymon. Humana New York, 219-292.

Bobroff B.L., Lentz A., Turner E.R., 2009. Food/drug and drug/nutrient interactions: what you should know about your medications. Univ. Florida IFAS Extens., FCS8092, 1-10.

Boullata J.I., 2010. An introduction to drug-nutrient interactions. Handbook of drug-nutrient interactions. Ed. J.I. Boullata, V.T. Armenti. Humana New York, 3-25.
Boullata J.I., 2010. Drug disposition in obesity and protein-energy malnutrition. Proc. Nutr. Soc. 69, 543-550.

Boullata J.I., Hudson M.L., 2012. Drug-nutrient interactions: A broad view with implications for practise. Acad. Nutr. Diet. 112, 4, 506-517.

Braun L., 2012. An introduction to: drug-nutrient interactions. IMER Meet March, Monash Univ., 1-41.

Bushra R., Aslam N., Khan Y.A., 2011. Food-drug interactions. Oman Med. J. 26 (2), 77-83.

Custodio M.J., Wu C.Y., Benet Z.L., 2008. Predicting drug disposition, absorption/elimination/transporter interplay and the role of food on drug absorption. Adv. Drug Del. Rev. 60, 717-733.

FDA, 2013. Avoid food-drug interactions. A guide from the National Consumer League and U.S. Food Administration Avoid Food-Drug Interactions. [online], http:// www.fda.gov/downloads/Drugs/ResourcesForYou/ Consumers/BuyingUsingMedicineSafely/EnsuringSafeUseofMedicine/GeneralUseofMedicine/UCM229033. pdf [access: May 2013].

Fragoso R.L., Esparza R.J., 2013. Fruit/vegetable-drug interactions: Effects on drug metabolizing enzymes and drug transporters. Intech, 1-34.

Frankel H.E., 2003. Drug interactions: Basic concepts. In: Handbook of food-drug interactions. Eds J.B. McCabe, H.E. Frankel, J.J. Wolfe. CRC Boca Raton, 37-45.

Lourenço L., 2001. Enteral feeding: Drug/nutrient interaction. Clin. Nutr. 20 (2), 187-193.

McCabe J.B., Frankel H.E., Wolfe J.J., 2003. Monitoring nutritional status in drug regimens. Handbook of food-drug interactions. Eds J.B. McCabe, H.E. Frankel, J.J. Wolfe. CRC Boca Raton, 89-121.

Moss M., 2007. Drugs as anti-nutrients. J. Nutr. Environ. Med. 16 (2), 149-166.

Mukherjee K.P., Ponnusankar S., Pandit S., Hazam K.P., Ahmmed M., Mukherjee K., 2011. Botanicals as medicinal food and their effects on drug metabolizing enzymes. Food Chem. Toxicol. 49, 3142-3153.

Robinson N.G., 2007. Herbs and foods that alter drug metabolism. [online], http://csuvets.colostate.edu/pain/articlespdf $/$ herbs $\% 20$ and $\% 20$ foods $\% 20$ that $\% 20$ alter $\% 20$ drug\%20metabolism.pdf [access: May 2013].

Scheen J.A., 2007. Diabetes, obesty and metabolic syndrome. In: Nutrient-drug interactions. Ed. A.K. Meckling. CRC Taylor and Francis Boca Raton, 5-17.

Tamer C.E., Karaman B., 2006. Greyfurt Suyu ve İlaçlarla Etkileşimi. GIDA 31 (2), 101-106.

Wallace J.M., Gerencser M., Surley P., 2013. Drug-nutrient depletions and known interactions. Nutritional 
Solutions. [online], www.nutritional-solutions.net [access: 2013].

Wunderlich M.S., 2004. Food and drug interactions. Handbook of drug interactions. A clinical and forensic guide. Eds Ed. A. Mozayani, P.L. Raymon. Humana Press, 379-393.

Yaheya M., Ismail M., 2009. Drug-Food Interactions and Role of Pharmacist. Asian J. Pharm. Clin. Res. 2, 4, $1-10$.

Received - Przyjęto: 23.06.2013

Accepted for print - Zaakceptowano do druku: 2.10.2013
Yao T.H., Luo N.M., Hung L.B., Chiang T.M., Lin H.J., Lii K.C., Huang C.Y., 2012. Effects of chitosan oligosaccharides on drug-metabolizing enzymes in rat liver and kidneys. Food Chem. Toxicol. 50, 1171-1177.

Zyl V.M., 2011. The effects of drugs on nutrition. S. Afr. J. Clin. Nutr. 24 (3), 38-41.

For citation - Do cytowania

Ötles S., Senturk A., 2014. Food and drug interactions: A general review. Acta Sci. Pol., Technol. Aliment. 13(1), 89-102. 